\title{
Din Hizmetleri Açısından Caminin Yeri ve Önemi*
}

NESIMI YAZICI

PROF. DR., ANKARA Ü. ILLÂHIYAT FAKÜLTESI

e-posta: nesimiyazici@mynet.com

\begin{abstract}
The Place and Importance of the Mosque relating the Religious Services. This short paper analyzes the concepts of religion, mosque, and service. In the following line, we consistently pointed out the mosques which is described as Bayt-ullah/the house of Allah, are not only the praying place, at the same time they are the grounds for implementing some activities, public services that gains the grace of Allah. In this context, we called attention the concept of "imar" / public improvements mentioned in the verse of Qur'an (Tawba 17, 18, 19). This word can be translated as "to enliven". As far as enliven concerned it is a main duty to all believers to make the mosques well populated, prosperous and decorative.
\end{abstract}

key words

Mosque, Service, Religious Service, Religion, Public Improvements, To enliven.

Kanaatimce tebliğimize, bize verilen başlıkta yer alan üç kelime; Din, Cami ve Hizmet kelimeleriyle bunlar arasındaki ilişkiyi, özlü biçimde açıklayarak başlamamız yerinde olacaktır. Burada Din denildiğinde kastedilen İslâm'dır. Cami ise İslâm'ın ilk müessesesi ve aynı zamanda da dünya durdukça duracak mabedidir. Hizmet'i İslâm ve onun mabedi Cami'yle birlikte kullandığımızda ise anlaşılan, Cami'de yapılabilecek din hizmetidir.

Din hizmeti denildiğinde öncelikle ibadeti düşünmekteyiz. Cami de ibadet yeridir. İbadet önemliyse ki öyledir, Cami de ibadet yeri olduğu için

* Bu metin Diyanet İşleri Başkanlığı (Ankara 3 Ekim 2005)'nca Camiler ve Din Görevlileri Haftası dolayısıyla düzenlenen Din Hizmetleri Açısından Cami, Dernek ve Vakıfların Yeri ve Önemi paneline tebliğ olarak sunulmuştur. 
önemlidir. Cami ve ibadet birlikte kullanıldığında, doğal olarak öncelikle aklımıza Namaz gelmektedir. Bununla birlikte Cami'de yapilabilecek ve yapılması da gereken tek ibadet Namaz değildir. Sanırım bu noktada, birkaç cümle ile de olsa, İbadet konusunu hatırlamamız yerinde olacaktır.

Bilindiği gibi sözlükte İbadet; boyun eğme, alçak gönüllülük, itaat, kulluk, tapma, tapınma gibi kelimelerde karşıllı̆ını bulurken, İslâm literatüründe biri özel, diğeri genel olmak üzere iki terim anlamı kazanmış bulunmaktadır. Buna göre özel anlamında ibadet; mükellefin Yaratan'ına karşı sayg1 ve itaatini simgeleyen, Allah ve Resûlü tarafından yapılması istenen belirli davranış biçimleridir. Fıkıh'ta da ibadetin yaygın kullanımı bu şekildedir ve namaz, oruç, zekât ve hac gibi İslâm'ın temel şartları yanında kurban kesme, itikâf, Kur'ân okuma, hayır ve infakta bulunma, dua etme gibi diğer bir kısım dinî davranışları içerir. Genel ve daha kapsamlı anlamında ise ibadet; mükellefin Allah'a karşı duyduğu saygı ve sevginin neticesi olarak O'nun rızasına uygun davranma çabalarını ve bu hedefe yönelik olarak yapmış olduğu iradî davranışlarının bütününü ifade etmektedir. ${ }^{1}$ Yani dince iyi, güzel ve doğru olarak nitelenen bütün davranışlar, ibadet kapsamı içerisinde değerlendirilmektedirler. Kulluğun en önemli gerek ve göstergelerinden biri olması dolayısıyla ibadetler, Kur'ân-1 Kerîm'de genelde ilkeler şeklinde ve özlü ifadelerle belirtilirken, Hz. Peygamber'in Sünnet'inde ayrıntılarıyla açıklanmış bulunmaktadır. ${ }^{2}$

Din hizmetleri açısından Cami'nin yeri ve önemi denildiğinde bizim düşündüğümüz, Cami'nin Müslüman'ın hayatının merkezinde bulunması ve dince yapılması veya sakınılması istenen bütün davranışlarının, Cami ile ilişkilendirilmiş olmasıdır. Bizce bu fikir kaynağını, Kur'ân-ı Kerîm ve onu yaşanılır bir gerçek olarak şekillendiren Hz. Peygamber (SAV)'in Sünnet'inden almaktadır.

Bilindiği gibi Cami karşılı̆̆ı olarak Mescid kelimesi, kitabımız Kur’ân-1 Kerîm'in muhtelif ayetlerinde tekil veya çoğul haliyle, İslâm mabedinin ismi veya sıfat tamlaması şeklinde geçmektedir. ${ }^{3}$ Hz. Peygamber'in çok

1. Ahmed Hamdi Akseki, İslâm Futrî, Tabî̂ ve Umumî Bir Dindir, İstanbul, 1968, s. 287-288; Mustafa Sinanoğlu, "İbâdet (Etimoloji ve Tanım)", DİA., c. XIX, s. 233; Ferhat Koca, "İbâdet (İslâm'da İbâdet)", DİA., c. XIX, s. 240, 241; Bekir Topaloğlu, "Din (II. Din ve Vicdan Hürriyeti, B. İslâm'da)", DİA., c. IX, s. 324; Vecdi Akyüz, Mukayeseli İbadetler İlmihali, İstanbul, 1995, c. I, s. 3-21.

2. ez-Zâriyât, 56. "Ben cinleri ve insanları, ancak bana kulluk etsinler diye yarattım". Ayr. bkz. Hadis kitaplarının ilgili bâb, fasıl veya bölümleri.

3. Muhammed Fuad Abdülbaki, el-Mu'cemü'l-Müfehres li-Elfâzi'l-Kur'âni'l-Kerîm, Beyrut, Tarihsiz, s. 345: Ahmet Önkal-Nebi Bozkurt, "Cami", DİA., c. VII, s. 46-47; Johs Pedersen, "Mescid", İA., c. VIII, s. 1-2. 
sayıdaki Hadis'inde de Mescid yani Cami konu edinilmiş bulunmaktadır. Ayrıca Peygamber'imizin hayatının pek önemli bir bölümü Mescid'de, yani Mescid-i Nebevî'de geçmiş, bunun sonucunda onun hayatını okuyanlar kendisini, çoğu defa Mescid'inde, Sahabesi ve/veya diğer insanlarla ilişki içerisinde görmüşlerdir.

İslâm'da Cami'nin yeri ve önemi, bunun yanında Müslüman'ın Cami ile ilişkisini konu edinen ayetler içerisinde üçü var ki, kanaatimizce onları bu vesile ile bir defa daha hatırlamamız yerinde olacaktır. Dokuzuncu sure olan Tevbe Suresi'nin 17, 18 ve 19. ayetlerinde "En-ya'murû mesâcidallahi... İnnemâ ya'muru mesâcidallahi... Ve imârete'l-mescidi... " ifadeleriyle "Mescidlerin İmarı" konu edilmektedir. Buna göre; Diyanet İşleri Başkanlığı'nın kurum adına halen Din İşleri Yüksek Kurulu Başkan ve Üyesi olan Dr. Muzaffer Şahin ve Doç. Dr. Halil Altuntaş'a hazırlattığı Kur'an-ı Kerim Meâli'nde bu ayetlerin meâli şu şekilde verilmiştir;" "Allah'a ortak koşanların, inkârlarına bizzat kendileri şahitlik edip dururken, Allah'ın mescitlerini imar etmeleri düşünülemez. Onların bütün amelleri boşa gitmiştir. Onlar ateşte ebedî kalacaklarıdır. Allah'ın mescitlerini, ancak Allah'a ve ahiret gününe inanan, namazı dosdoğru kılan, zekâtı veren ve Allah'tan başkasından korkmayan kimseler imar eder. İşte onların doğru yolda bulunanlardan olmaları umulur. Siz hacılara su dağıtmayı ve Mescid-i Haram'ın bakım ve onarımını, Allah'a ve ahiret gününe iman edip Allah yolunda cihad eden kimse(lerin amelleri) gibi mi tuttunuz? Bunlar zâlim topluluğu doğru yola erdirmez".

Görüldüğü gibi bu meâlde "Mescidlerin İmarı" ilk iki ayette, kelimenin dilimize de geçen haliyle, doğrudan "imar", üçüncü ayette ise "bakım ve onarım" şeklinde çevrilmiştir. Burada imardan kast edilenin ne olduğu açıklanmamıştır. Kanaatimce bu mefhumun biraz açılması, konumuzun daha iyi anlaşılması yönünden faydalı olacaktır. İmarın hem maddî ve hem de manevî imar şeklinde anlaşılması mümkündür ve Kur'ân-1 Kerîm'in meâl ve tefsiri ile ilgilenen bir kısım araştırmacı da bu yöne dikkat çekmiş bulunmaktadır. Nitekim Hamdi Yazır ${ }^{5}$ ayetlerin meâllerini "ma'mur etmek" şeklinde vermiş, tefsirinde ise ; "Mescidin imareti iki manaya gelir. Birisi binast ve tecdidi, birisi de ziyareti ve içinde bulunup ibadet edilmesidir" şeklinde izah ederek, maddî ve manevî imardan bahsetmiştir. Ona göre Kâbe'yi ziyarete umre denilmesi, mescidlere çok gidip, içlerinde çok zaman geçirenlerin de "ummâr-ı mesâcid" tarzında nitelendirilmeleri bununla ilgilidir. Hamdi Yazır devamla; bir mescidin ma'muriyyeti iki cihetin bir arada bu-

4. Ankara, 2001, s. 188.

5. Hak Dini Kur'an Dili, İstanbul, Tarihsiz, c. IV, s. 2478-2486. 
lunmasıyla olur. Birincisi maddî umranıdır ki binası, tamirâtı, temizlenmesi, döşenmesi, aydınlatılması ve bunların devamıyla ilgili hususlardır. İkincisi ise manevî umranıdır ki içinde Allah için ibadet, zikir, tedrîs-i ulûm gibi tâât ve fazîletlerin ve bunların tamamlayıcısı olan diğer hususların yerine getirilmesidir, demektedir. Süleyman Ateş de söz konusu ayetlerin tefsirini yaparken; "Mescid'i imâr, sadece yapısını onarmak değil, aynı zamanda ibâdet edenlerle dolup şenlenmesidir" demektedir. Aynı duruma diğer bazı meâl ve araştırmalarda da dikkat çekilmiş bulunmaktadır. ${ }^{7}$ Nitekim DİA.'da bu konuda; Tevbe 18 ayeti ile diğer bir kısım "ayet ve hadisleri göz önünde bulunduran İslâm âlimlerinin çoğuna göre söz konusu naslarda yer alan "imar" tabiri camilerin inşası, onarımı ve döşenmesi, aydınlatılması ve temiz tutulması gibi maddî imarı içine aldığı gibi oralarda ibadet etmek, Kur'ân okumak ve okutmak, ilim öğrenmek ve ögretmek gibi manevî imar faaliyetlerini de ihtiva eder" kaydına yer verilmiştir. ${ }^{8}$

Bu vesile ile son dönemde meâl ve tefsir çalışması yapanların bir kısmının, "imar" teriminin karşılığı olarak, "şenlendirmek/şeneltmek" kelimesini kullanmakta olduğu görülmektedir ki, kanaatimize göre bu isabetli ve üzerinde durulması gereken bir seçimdir. ${ }^{9}$ Çünkü "şenlendirmek", Türk kültür tarihinde, hem maddî ve hem de manevî yönüyle hizmeti içeren, geniş kapsamlı bir kelimedir. Nitekim Osmanlı Tarihi'nde şenlendirmek; boş, bakımsız ve hattâ bazı sebepler dolayısıyla tehlikeler içeren bir yerin/arazinin, çeşitli yönleriyle değerlendirilmesi anlamında kullanılmıştır. Bu durumu birkaç örnekle açıklamamız yerinde olacaktır. "Değirmencili köyüne vaktiyle iskân edilen Gürcü göçmenler burayı şeneltmişlerdir(/şenlendirmişlerdir)", "Eknâf-ı memâlik baştan başa koz içi gibi dolup şeneldi (şenlendi)", "Az müddet içinde ol vilâyet evvelki gibi şeneldi (şenlendi)". ${ }^{10}$

Osmanlılar hem başlangıçtaki fetihler döneminde ve hem de daha sonra sınırların daraldığı devrelerde, çift yönlü bir iskân siyaseti gütmüşlerdi.

6. Yüce Kur'ân'ın Çă̆daş Tefsiri, İstanbul, Tarihsiz, c. IV, s. 42.

7. Muhammed Hamidullah, İslâm Müesseselerine Giriş, Çev. İhsan Süreyya Sırma, İstanbul, 1981, s. 65.

8. Mehmet Şener, "Cami (III. Dinî Hükümler)”, DİA.,c. VII, s. 91.

9. Örnek olarak bkz. Süleyman Ateş, Yüce Kur'ân’ın Çă̆daş Tefsiri, c. IV, s. 42; Hüseyin Atay, Kur'an Türkçe Çeviri, Ankara, 2002, s. 188; Salih Akdemir, Son Çağrı Kur'an, Ankara, 2004, s. 188; Hasan Basri Çantay, Kur'ân-ı Hakîm ve Meâl-i Kerîm, İstanbul, 1965, c. I, s. 275, d. not. 20.

10.Birinci örnek; Türkiyede Halk Ağzından Söz Derleme Dergisi, İstanbul, 1942, c. III,s. 1281; ikinci ve üçüncü örnekler XV. yüzyıla ait; Tanıklarıyla Tarama Sözlüğü, Ankara, 1953, c. II. S. 863; Ayr. bkz. Tanıklarıyla Tarama Sözlüğü, Ankara, 1953, c. I, s. 662; Aynı eser, Ankara, 1954, c. III, s. 654; Aynı eser, Ankara, 1957, c. IV, s. 722; Osmanlıcadan Türkçeye Söz Karşılıkları Tarama Dergisi, İstanbul, 1934, s. 1203. 
İşte bu siyasetin uygulanması sırasında, şenlendirmek terimiyle sıklıkla karşllaşlmaktadır. Buralarda şenlendirmek terimi boş, harap ve sahipsiz yerler veya yeni fetih edinilen bölgelerin iskan edilerek ziraata açılması, üretim yapılır hale getirilmesi karşılığında kullanılmıştır. ${ }^{11}$

Bilindiği gibi Osmanlılar döneminde, sözlüklerde; engel, geçit, boğaz, set, hudut bölgelerinde, dağlar arasında güçlükle geçilen boğaz manalarına gelmek üzere Farsça der: geçit ve bend: tutmak kelimelerinden derbend ismi oluşturulmuştur. Osmanlı devlet teşkilâtı içerisinde derbendleri XIV. yüzyılın ikinci yarısında görmemiz mümkün olmakla birlikte, teşkilâtlanmiş bir kurum olarak derbendler, II. Murad (1421-1451) ve II. Mehmed (1451-1481) devirlerinden itibaren takip edebilmektedir. Bu teşkilât sayesinde, yolların ve geçitlerin emniyeti sağlanmaktaydı. Nehirlerin geçit vermediği, köprü bulunmayan yerlerde halkın karşı sahile, oradakilerin de beriye ulaştırılması için bazı kimseler kayık işletmekle görevlendirilmekteydiler. Gerektiğinde kendi bölgelerinde yolculara rehberlik de eden derbendciler, görev mahallerinde yolcu ve tüccarın malına gelen zararı da öderlerdi. Önemli geçit yerlerinde, köprülerde, korunması gereken yol boylarında kurulan derbendler, deniz kenarlarında da kurulur ve kıyının kontrolü görevini üstlenirdi. Şüphesiz teşkilâtın en önemli görevi, belgelerin diliyle söylemek gerekirse; "mahûf ve muhatara olan, hifz ve hurâseti lazım olmağın, kuttâ-ı tarîk ve haramîden halî olmayan" yerlerde eşkıyalar ve seyahat hürriyetini kısitlayan diğer gruplarla mücadele etmekti. Yani derbendciler issız yerleri şenlendirirlerdi.

Ulukışla-Ereğli arasında bulunan Çavuşlar (Çavuşlu) köyü, tehlikeli ve önemli bir geçit noktasında bulunmaktaydı. Burada bir han ve cami inşa edilmiş, ayrıca bir kısım insanlar buraya getirilerek yerleştirilmişlerdi. Neticede topraksız, evsiz insanlar ekecek arazi ve yurt sahibi oldukları gibi, boş arazi de şenlendirilmişti. Bir başka örnek; Premadi vilâyetiyle ilgili defterdeki şu kayıttır; "Tîmar-ı Fîruz ve karındaşları Iskra ve Martin vîranedür şeneldüp nöbetçi etmekle Paşa'dan biti almuşlar şimdiki halde Pâdişah-l cihân-güşâ hazretlerine, arz olundu mukarrer duttu ...". ${ }^{12}$

Kozağacı köylülerinin Söğüt'e göçmeleri üzerine Bilecik Kadısı'na gönderilen 2 Eylül 1577 tarihli fermanda; “... karye-i mezkûrenin üzerine va-

11. “XVIII. yüzyılda Osmanlı İmparatorluğu'nun iskân politikası, boş ve harâp yerlerin şenlendirilmesi ve ziraate açılmast istikametinde yürütülmüştür". Yusuf Halaçoğlu, XVIII. Yüzyılda Osmanlı İmparatorluğu’nun İskân Siyaseti ve Aşiretlerin Yerleştirilmesi, Ankara, 1988, s. 58-78, 144; Yusuf Halaçoğlu, "Kolonizasyon ve Şenlendirme", Osmanl, Ankara, 1999, c. IV, s. 581-586.

12.Geniş̧ bilgi için bkz. Cengiz Orhonlu, Osmanlı İmparatorluğunda Derbend Teşkilâtı, İstanbul, 1967. 
rubteftiş ve tefahhus idüb göresin ...eğer yerleri bilfiil kimesne tasarrufunda olmayub mahlûl ise âhardan bazı reâyâ getirdilüb temekkün itdirmekle mi mamur olur. Ve bilcümle karye-i mezbûre her ne vechile mamur olmak mümkün ise tedarik idüb ve yazub bildiresin". ${ }^{13}$

Osmanlı tarihinin başlarında tasavvuf erbabının, devletin de desteği ve yönlendirmesiyle, özellikle ıssız ve tenha yerlerde zâviye ve tekkeler tesis ettikleri bilinmektedir. Ömer Lûtfi Barkan bu konuyla ilgili dikkat çekici örnekler vermiş bulunmaktadır. ${ }^{14}$ Rumeli'ye ordularla birlikte geçen dervişler, yollar boyunca zâviyeler ve tekkeler meydana getirmişlerdi. Bölgelerinde gelip geçen yolculara hizmet etmekte olan bu dervişlere, bulundukları yerler evlâdlık vakıf olarak kaydedilmişti. Nitekim Dimetoka kazasında medfun Esseyyid Ali nâm-1 diğer Kızıl Sultan (Kızıl Delü)'a "Diyar-ı Rumeli şeref-i İslâmla müşerref oldukta bile geçüp ...", burada kurduğu zaviyesine inen yolculara, çevresindekilerle birlikte hizmet etmesi mukabili, evlatlık vakıf olarak Tatar Viranı ve Tatarlık gibi mezralar,, 804/14011402 tarihli mülknâme ile verilmiş ve söz konusu topraklar, bu hizmete devam ettikleri sürece, Kızıl Delü oğullarının tasarrufunda bulunmuştur. Çünkü onlar Allah'ın dağında 58 Müslüman ve 23 Gayrimüslim haneli bir köy oluşturarak, asayişi ve emniyetli yolcuğu temin etmişler, çevreyi şenlendirmişlerdir.

Sivas'a bağlı bulunan Çil köyü isimli mezra tehlikeli bir geçit yeri idi. Derviş Bahadır, Derviş Sevindik, Derviş Ümmet buraları iltizam ederek, bir zâviye inşa etmişler, gelen geçen yolculara hizmet ederek çevreyi şenlendirmişlerdi."Kölek Kilisâ nâm viraneleri tarîk-i âmda şenledüb zâviye bünyâd idüb âyende ve revendeye hizmet etmeye..." .

Son bir örnek Saruhan'da dağ eteğinde Şucâ Abdal, Sinan, İsmail, Mustafa, Ali ve Kaygusuz, dervişlerle birlikte sipahiden bir yer tapulamışlar "taşın ağacın arıdep yurd edinip ihya etmişler zaviye kurmuşlar ve sultandan şenlettikleri yer için vakıf beratı almışlar"dır. ${ }^{15}$ Bir defa daha tekrar edecek olursak, tasavvuf ehliyle ilgili olarak; gelişmeye müsait, boş ve bu haliyle birakılırsa tehlikeli olabilecek yerleri ziraat yapılabilir hale getirerek, ayrıca da burada bir kısım hizmetleri halka karşlıksız olarak vermeye, belgelerin diliyle şenlendirmek denmekteydi. Öyleyse Mescidlerin ve daha yaygın kullanımıyla Camilerin şenlendirilmesi denildiğinde, şüphesiz buraların maddî imarı kadar, manevî imarlarının da hedeflenmesi ve bu doğrultuda

13.Ahmet Refik, Anadolu'da Türk Aşiretleri, İstanbul, 1989, s. 30.

14."Kolanizatör Türk Dervişleri”, VD., c. II (Ankara 1942), s. 277-353.

15.Halil İnalcık, "Osmanlı Tarihine Toplu Bir Bakış", Osmanlı, Ankara, 1999, c. I, s. 49. 
çaba gösterilmesinin anlaşılması gerekmektedir ki, bu da inananlara Cenab-1 Hakk'nn yüklediği bir görevdir.

Kanaatimce şimdi de sıra Camilerin hangi din hizmetlerinde kullanılabilecekleri konusuna açıklık getirmeye gelmiş bulunmaktadır. Kur'ân-ı Kerîm'e ve Hz. Peygamber'ín Sünnet'ine baktığımızda, Camilerdeki din hizmetlerinde önceliğin, ibadette yani özellikle namazda bulunmakla birlikte, bunun çok geniş bir hizmet yelpazesini de içermekte olduğunu görebiliriz. Nitekim Hz. Peygamber (SAV)'in Sünneti, özellikle de Mescid-i Nebevî'deki uygulaması bu yöndedir.

Bilindiği gibi Hz. Peygamber Mekke'den Medine'ye Hicret etmiş, 24 Eylül 622 Cuma günü Medine'ye gelmiştir. Misafirlik için yapacağı tercih dolayısıyla kimseyi kırmak istemeyen Peygamberimiz, devesinin serbest bırakılmasını, onun çöktüğü yere en yakın evde konaklayacağını bildirmiş, bu sırada Mü'minûn suresinin 29. ayetinde bulunan ve Hz. Nuh'a atfedilen; "Ey Rabbim! Beni bereketli bir yere kondur. Sen konuk edenlerin en haytrlistsın” duasını tekrarlamıştır. Sonuçta Peygamberimiz Ebû Eyyûb el-Ensârî̀ye misafir olmuş, Mescid-i Nebevîyi üzerinde inşa etmek için de Sehl ve Süheyl isimli iki kardeşe ait olan arsa, ücreti ödenerek satın alınmıştır. Eylül 622'de başlayan inşaatta Hz. Peygamber sahabesi ile birlikte çalışmış ve Nisan 623'te Mescid-i Nebevî’nin yapımı tamamlanmıştır.

İlk şekli ile Mescid-i Nebevî oldukça da mütevazı ve sade bir yapı idi. Zaten onun büyüklüğünü yapısının azametinde aramamanın gereği de açıktır. ${ }^{16}$ Zaman içerisinde çeşitli genişletme, tamir veya yenileme çalışmalarına konu oluşturan Peygamberimizin Mescid'i, kendisinin hayatta bulunduğu sürece O’nun ve Medine'deki Müslümanların, İslâm ülkesinin genişlemesine paralel olarak da bütün İslâm toplumlarının hayatlarının merkezinde yer almıştı.

Mescid-i Nebevîyi İslâm'ın ilk müessesesi olarak nitelemek mümkündür. Bu bakımdan o, Hz. Peygamber ve Hulefâ-i Râşidîn dönemlerinde çok geniş bir işleve sahiptir. Bunların birkaçını başlıklar olarak hatırlamamız yerinde olacaktır. Mescid-i Nebevî her şeyden önce ibadet mahalli idi. Peygamber Efendimiz, bir başka sebep yoksa, namazını burada kılar ve kıldırır, dua ederdi. Namaz öncesi veya sonrasında sahabesi ile ve diğer insanlarla burada sohbet eder, dinin gereklerini burada öğretir, zikir ve tevbe tavsiye

16.Mescid-i Nebevî̀yi konu edinen çok sayıda çalışma bulunmaktadır. Biz örnek ve hareket noktası oluşturmak üzere birkaçını veriyoruz. Nebi Bozkurt-Mustafa Sabri Küçükaşcı, "Mescid-i Nebevî", DİA., c. XXIX, s. 281-290; İbrahim Ateş, "Mescid-i Nebevînin Yapıldığı Günden Bu Yana Geçirdiği Genişletme Girişimleri”, VD., c. XXIV (Ankara 1994), s. 5-50. 
ederdi. İslâm toplumunu ilgilendiren bütün meseleler çoğunlukla burada müzakere edilirdi. Elçiler burada kabul edilir, lüzumu halinde yaralıların tedavisi, mahkemeler, hattâ folklor gösterileri diye nitelenebilecek bir k1sım faaliyetler de Mescid-i Nebevî'de gerçekleştirilebilirdi. Peygamber Mescidi kültür merkezi, danışma meclisi, misafirhane, hazine, hapishane olarak da kullanılmıştı. Bununla birlikte oradaki faaliyet içerisinde, Suffe denilen bölümde kalanların öncelikli hedefi oluşturduğu eğitim-öğretim çalışmaları, çok önemli bir yer tutmaktaydı. ${ }^{17}$ Bilindiği gibi Mescid-i Nebevînnin duvarına dayalı olarak yapılan odalarda Hz. Peygamber eşleriyle birlikte kalırdı. Her biri çok sayıda örnekle delillendirilebilecek bu işlevleri dolayısıyla Mescid-i Nebevî'nin, hem Peygamberimizin hayatında ve hem de İslâm toplumunun yaşamında, vazgeçilmez bir önceliğe sahip olduğu yeterince açık olduğundan, bu kadarlık bir hatırlamanın yeterli olduğunu düşünmekteyiz. ${ }^{18}$

Hz. Peygamber hayatta iken Medine'de Mescid-i Nebevî haricinde, daha önce yaptırılmış bulunan Kubâ Mescidi ${ }^{19}$ ve ayrıca çeşitli kabilelere ait, bazılarında Peygamberimizin de namaz kıldığı dokuz adet Mescid vardı. Bunlarda vakit namazları kılınırdı. ${ }^{20}$ Uzak bölgelerde Cuma kılınan Mescidlerin de bulunmuş olması mümkündür. Nitekim günümüzde Riyad ile Dahran arasında Cuvâsa'da Cuma kılınan bir Mescidden bahsedilmektedir. ${ }^{21}$

Camiler, Müslümanların çoğunluk veya azınlık olarak bulundukları bütün coğrafyalarda var olmuşlardır/olacaklardır. Bilmediğimiz, tanımadığımız bir yerleşim yerinde Müslümanlarının bulunup bulunmadıklarının en açık göstergesi Camilerdir. Bir yerde Caminin bulunması, oranın halen veya bazen de geçmişte Müslüman beldesi olduğunu anlamamıza imkân verir.

17.Mustafa Baktır, İslâm'da İlk Eğitim Müessesesi Suffa Ashabı, İstanbul, 1984.

18.Mescid-i Nebevînnin fonksiyonlarıyla ilgili birçok çalışmada yeterli bilgi bulmak mümkündür. Biz örnek olarak birkaçını vermekle yetiniyoruz. Johs Pedersen, "Mescid", İA., s. 2-5, 16-23; Ahmet Önkal-Nebi Bozkurt, "Cami", 47-53; Muhammed Hamidullah, İslâm Müesseselerine Giriş, s. 55-73; Mustafa Ağırman, Hz. Muhammed (S.A.V) Devrinde Mescid ve Fonksiyonlarl, İstanbul, 1997, s. 109-182; Ahmet Güner, "Asr-1 Saâdet'te Mescidler/Camiler ve Fonksiyonları", Bütün Yönleriyle Asr-ı Saâdet'te İslâm, İstanbul, 1995, c. IV, s. 155-21; Ahmet Önkal, "Asr-1 Saadet'te Mescid'in Önemi ve Yaptığı Görevler”, Diyanet Dergisi, c. XIX, S. 3 (Ankara 1983), s. 49-55; Ziya Kazıc1, "Tarih Boyunca Cami ve Gördüğü Hizmetler", Diyanet Dergisi, c. XXII, S. 4 (Ankara Ekim-Kasım-Aralık 1986), s. 8-10

19.Hüseyin Algül-Nebi Bozkurt, "Mescid-i Kubâ", DİA., c. XXIX, s. 279-281.

20.Ahmet Önkal-Nebi Bozkurt, "Cami”, s. 48; Muhammed Hamidullah, İslâm Müesseselerine Giriş, s. 52; Câhid Baltacı, "İslâm Medeniyetinde Cami", Marmara Üniversitesi İlâhiyat Fakültesi Dergisi, S. 3 (İstanbul 1985), s.228.

21.Muhammed Hamidullah, A.g.e., s. 53; İlerleyen dönem için bkz. Yılmaz Can, "İlk İslâm Mescidlerine Genel Bir Bakış", Diyanet İlmî Dergi, c. XXXI, S. 4 (Ankara Ekim-Kasım-Aralık 1995), s. 89-114. 
Bizim ecdadımız Müslüman Türkler de Cami yapımına pek büyük önem ve değer vermişlerdir. Osmanlı başkentine bakan bir yabancı (Le Corbusier); "İstanbul'da veciz bir doku görülür: Bütün Fânîlerin evleri ahşap ve Allah'in evleri ise taştandır" derken, hayatın geçiciliği inancındaki ecdadımızın, ahşaptan dantele gibi işledikleri kendi evlerinin kısa ömrüne karşıllık, her birini Beytullah yani Allah'ın Evi olarak niteledikleri mukaddes mabetlerinde kullandıkları kalıcı malzemeye, böylece dünya durdukça durmasına verdikleri öneme dikkat çeker. ${ }^{22}$

Camilerin tarihi ile ilgili panoramik de olsa bir çerçeve çizdikten sonra kanaatimce şimdi konuşmamızın başında söz konusu ettiğimiz, Tevbe suresinin 17, 18 ve 19. ayetlerine bir defa daha dönebiliriz. Günümüzde camilerin imarı/şenlendirilmesi adına; resmî açıdan Diyanet İşleri Başkanlığı'na, gayrı resmî açıdan da inanan müminler olarak hepimize düşen görevler nelerdir? Biz neyi, ne kadar yapıyoruz? Hatalarımız, eksiklerimiz, kusurlarımız var mıdır? Daha neleri, nasıl yapabiliriz, yapmalıyı? Bütün bunlar ve benzeri sorulara eksiksiz ve fazlasız cevaplar bulabilmiş olmayı bütün samimiyetimle arzu ederdim. Fakat böyle bir cevap veya cevaplar bulamadım. Yalnızca düşünüyorum ve bütün inananların düşünmesini istiyorum. Camilerimizi bugünkü hallerinden daha iyiye nasıl götürebiliriz? Tek tek veya çoğu defa Müslümanların küçük birikimlerini vererek geniş katılımlarla, inançlarının göstergesi olarak yaptırdıkları camilerimizi nasıl daha faydalı hale getirebiliriz?

Mescid-i Nebevî örneği önümüzde durmaktadır. Tabiatıyla oradaki birçok faaliyet, o dönemin ve içinde bulunulan şartların gereği olarak camide yapılmıştır. Günümüzde mahkemelerin Camilerde yapılmasını istemek, Caminin ne demek olduğunu anlamamak demektir. Vergi gelirleri de Camide muhafaza edilecek değildir. Misafirlerimizi ağırlamak için daha uygun mekanlara ve imkânlara sahibiz. Ama Camilerimizi de yalnızca namaz vakitlerinde açılan, bu ibadetin tamamlanmasının hemen ardından da kilitlenen mekânlar olarak bırakmamamızın gerektiği açıktır. Allah'a ve ahiret gününe inanan, namaz kılan, zekât veren ve sadece Allah'tan korkan kimselerin O'nun Mescidlerini şenlendirmesi günümüzdekinden daha farklı olmall, olabilmelidir. Kanaatimce tarihimizde bu yolda uygun örneklerde bulunmaktadır. Nitekim başka bir kısım Müslüman topluluklarının geçmiş-

22.Diğerleriyle birlikte Osmanlı dönemi cami mimarisinin özlü bir anlatımı Semavi Eyice tarafından önce yapılmıș ("Cami”, Türk Ansiklopedisi, c. IX, s. 257-279; "Cami - Anadolu'da ve Rumeli'de Türk Mescid ve Camileri”, $\dot{I}$ A., c. VIII, s. 101-118), daha sonra elde edilen yeni bilgilerin ışı̆̆ında bu anlatım ("Cami - II. Mimari Tarihi”, DİA., c. VII, s. 56-90) geliştirilmiştir. 
leri gibi, Osmanlı tarihine bakıldığında da küçük mescidler, mahalle veya kasaba camileri görürüz. Buralarda cemaatle namaz kılınır, hutbe ve zaman zaman vaazlarla cemaatin dinî bilgileri tazelenir, eksikleri giderilir, çevredeki bir kısım yardım çalışmaları organize edilirdi. Bunları Hz. Peygamber döneminde Medine'de de bulunan küçük Mescidlere benzetebiliriz. Bununla birlikte bir de büyük mabetler vardı. Selâtin camiler, Ulu Camiler, merkez camiler vardı. İçlerinde çok sayıda ders halkalarıyla birer okul/ örgün eğitim-öğretim kurumu gibiydiler. ${ }^{23}$ Aynı zamanda da Ramazanda aynı anda üç-beş mukabelenin okunduğu, isteyenin seçtiği vaizin çevresinde kümelene bildiği yaygın eğitim merkezleriydiler. Külliyelerimiz vardı. ${ }^{24}$ Bunlarda merkezdeki Cami ile birlikte diğer birçok müştemilât bulunurdu ve din hizmetleri geniş bir yelpazede sürdürülürdü. Bütün bunlar camilerimizin Müslüman'ın hayatında daha etkin roller oynayabilmeleri için, inananların cami merkezli birer hayat sürdürebilmeleri yolunda bizlere engin tecrübeler sunmaktadırlar. Geliniz kaynağında Kur'ân-1 Kerîm'in ayetleri, Hz. Peygamber'in billurlaşmış Sünnet'i bulunan bu tecrübeleri günümüzün insanının da hizmetine sunalım. Bu yolda yeni fikirler oluşturalım, geliştirelim. Camilerimizi şenlendirme hedefine daha sıkı sarılalım. Bilelim ki Camiye yakın olmak Cenab-1 Hakk'a yakın olmaktır. Ne mutlu bu hedef doğrultusunda ilerleyebilenlere, ne mutlu Yüce Yaratıcı'nın rızasına uygun davranabilenlere!...

23.Bkz. Mehmet İpşirli, "Dersiâm", DİA., c. IX, s. 185-186.

24.Feridun Akozan, "Türk Külliyeleri", VD., c. VIII (Ankara 1969), s. 303-308; Bahaeddin Yediyıldız, "Sosyal Teşkilâtlar Bütünlüğü Olarak Osmanlı Vakıf Külliyeleri”, Türk Kültürü, S. 219, Yıl XIX (Ankara Mart-Nisan 1981), s. 262-271. 